\title{
Supporting Sense-making with Tools for Structuring a Concept Space: A Proposal for Design and Evaluation
}

\author{
Pengyi Zhang \\ College of Information Studies, 4105 Hornbake (South Wing) \\ University of Maryland, College Park, MD 20742 \\ pengyi@umd.edu
}

\begin{abstract}
This paper describes a research proposal to investigate sense-making processes in complex situations with the assistance of information systems. It presents the design of a sense-making tool to be integrated with a news retrieval system. The proposed user study aims to understand how users use this tool to establish and organize their conceptual models of a network of concepts and relationships.
\end{abstract}

\section{Introduction}

This paper proposes the design and evaluation of a sense-making tool that incorporates tools for structuring a concept space, such as concept maps, in which a user represents her emerging understanding of a problem or situation and is able to detect patterns.

Sense-making has been defined as "the process by which individuals (or organizations) create an understanding so that they can act in a principled and informed manner. Sensemaking tasks often involve searching for documents that are relevant for a purpose and then extracting and reformulating information so that it can be used. When a sensemaking task is difficult, sensemakers usually employ external representations to store the information for repeated manipulation and visualization." (PARC) People often encounter sense-making tasks, especially for situations or problems that are new and not so well understood (Dervin, 1992). Before any action to be taken or decision to be made for a task, we first need to accomplish the subtask of making sense of the situation. Part of sense-making involves establishing a network of connected concepts and relationships. Sense-making tools need to adapt to the domain. For example, intelligence analysts often deal with tasks that involve complex situations. They may need to constantly update their conceptual model of the situation as it evolves gradually or dramatically over time. For example, a political figure may suddenly become a focus of attention after certain events took place. An analyst's task may include tracking the events this person is or has been involved in, to make sense of the complicated ties and associations of the political figure as he/she relates to many countries, organizations, events, and other figures.

Such tasks are not easy. With the help of information retrieval systems, users may be able to get the relevant information from various sources; but the more challenging task is for users to filter through the possibly huge amount of information or dig into the possibly little information, to combine it with various other sources, such as previous knowledge and collaboration with other team members, to establish a conceptual structure (Lehmann, 1992; 
Novak and Cañas, 2006) of the situation, and to possibly suggest actions or decisions to take for the ultimate task. Some effort has been done in designing tools to support various parts of the process (Baldonado et. al, 1997; Gaines, and Shaw, 1995; Qu, 2007; Wright et. al, 2006).

It's very important to understand the users' sense-making process and how automated tools may help them with this process. Consequently, our main research question is:

How do users make sense of complex situations with the assistance of a sense-making tool?

Some sub-questions include:

1. What are the ways in which users represent their mental models and organize the rich network of concepts and relationships?

2. How and to what extend do the system conceptual structure and the user conceptual structure match and influence each other?

3. How does the users' conceptual model evolve?

4. What information do users search for and use to build the concepts and relationships in their conceptual models?

5. Does automatic extraction of concepts and relationships help users with their sense-making processes? (Do they use extracted results, and if so, how?)

6. Does the tool help users' sense-making processes and their task performance?

This paper is organized as follows:

Section 2 gives an example of a user's sense-making process extracted from her verbal protocol in previous user studies of a news retrieval system.

Section 3 briefly describes the design of the sense-making tool.

Section 4 describes the proposed research design and methodology.

Section 5 concludes with discussion of possible implications of the study.

\section{A Sample Sense-making Scenario}

This section presents a hypothetical example (inspired by a session in a user study) of how the envisioned tool would be used. The tool will be designed for intelligence analysts, integrated in Rosetta, a multilingual, multimedia news retrieval system. As part of a formative evaluation of Rosetta, we conducted a series of user studies (Zhang et. al, 2007). In each session, users were assigned a task that often involves finding information and making suggestions for judgment and decision making. As part of the data collection, users' think-aloud protocols were recorded when they were performing the tasks. 
We analyzed the think-aloud protocol of a user and recast in the form of concept maps to illustrate how concept maps might support a user's sense-making process. The task required users to produce a report identifying information to assess the influence of al-Bashir, the Sudanese president. Requested information included key figures, organizations, and countries who have been associated with al-Bashir, his rise to power, and groups who have resisted him and the level of success in their opposition. Users received some background information about al-Bashir and Sudan.

After reading the task background information, along with previous knowledge, a user established an initial understanding of the situation. The following conceptual model was reflected in her think-aloud protocol:

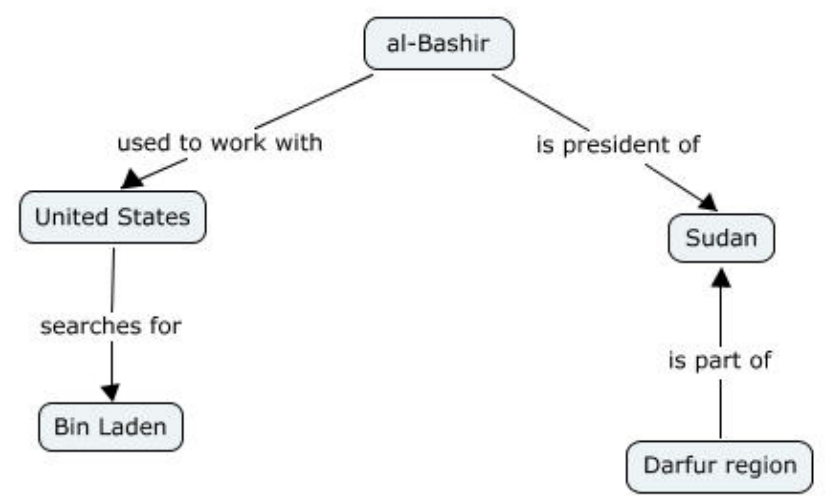

\section{Figure 1: Concept Map Representation of the Initial Conceptual Model of Task al-Bashir by User 28}

She then used a function that allowed her to do a search about a person, and find some additional information to enrich her understanding:

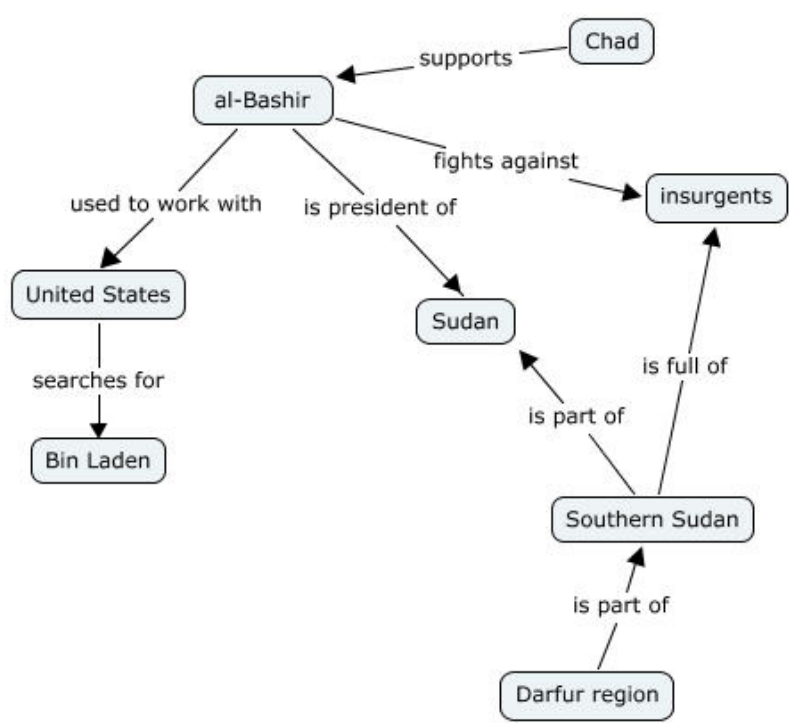

Figure 2: Concept Map Representation of the Interim Conceptual Model of al-Bashir Task by User 28 
In this model, the user identified that the insurgents are active in the area of Southern Sudan. She also updated the Darfur region as a part of Southern Sudan. The country of Chad is identified as supporting al-Bashir.

The user then used various search functions and pulled pieces of useful information together. Some of the useful information was saved to her notes to be used for the task report. The last conceptual model before the user started writing her report is shown in Figure 3:

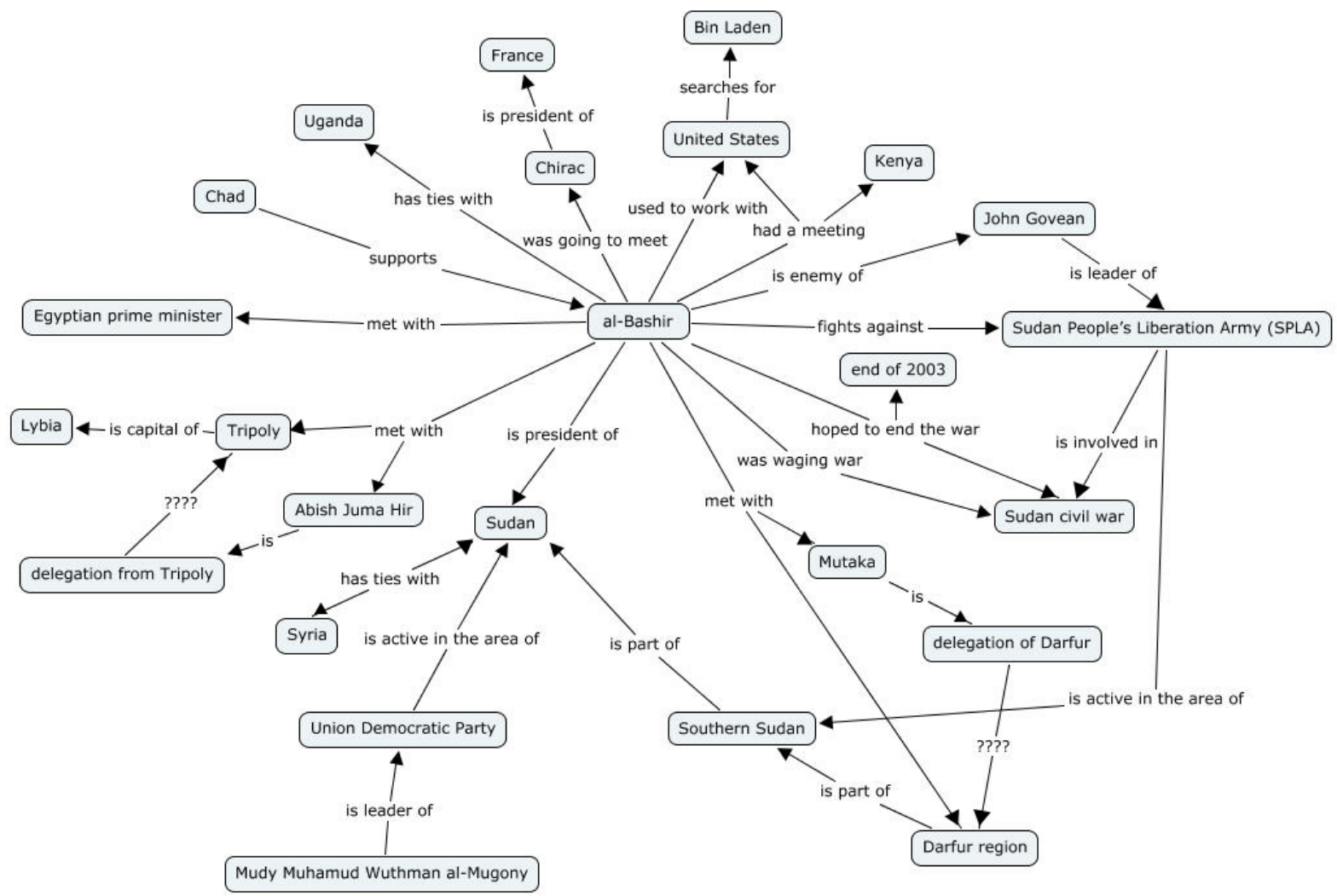

Figure 3: Concept Map Representation of the Final Conceptual Model of al-Bashir Task by User 28

As shown in the Figure 3, the user updated the group of insurgents in Figure 2 as the Sudan People's Liberation Army (SPLA) and identified its leader and involvement in the Sudan civil war. She also identified several ties with different countries, people, and organizations.

This reconstructed conceptual model is one way of representing the "sense" made by the user. There might be other equally good representations that the user may come up with.

\section{The Sense-making Tool}

Our sense-making tool is designed to assist users in building their conceptual model of a task situation by organizing their search results, identifying and recording concepts and relationships, and outlining a task report for further use. It is integrated as part of the news retrieval system, developed at IBM T. J. Watson Lab, which supports intelligence analysts to get access to news sources in various languages and media. The tool under design 
complements the system's search functions to provide better support for sense-making. The sense-making tool has the following major functions (see Appendix 1 for detail):

- Search: users can use the regular search box to issue a query, or initiate a search from the workspace on a particular part of the conceptual model;

- Manipulation of concepts and relationships in concept maps, templates, and outlines

○ Users can create concepts or relationships from the search results that are found useful;

- Users can attach a piece of evidence found in any text segment and its citation information to the relevant parts of their conceptual model;

- Users can merge, modify, and delete concepts and relationships in the workspace

- Display: users can switch between graphic and template-based displays of concepts and relationships;

- Information extraction: IE is used to automatically create concepts and relationships with different levels of user involvement.

The graphic display of the network of concepts and relationships may look similar to the conceptual models shown in Figures 1-3. An example of the template-based display (Fikes and Kehler, 1985) of a concept and its relationships is shown as below:

\begin{tabular}{|c|c|c|}
\hline Al-Bashir & & \\
\hline \multicolumn{3}{|l|}{ Attributes } \\
\hline Name/Alias & $\begin{array}{l}\text { Omar Hasan } \\
\text { Ahmad al-Bashir }\end{array}$ & $\begin{array}{l}\text { The Sudanese president, Omar Hassan Ahmad } \\
\text { Al-Bashir, today at a celebration... } \\
\text { Sudan Tribune - Jul 10, } 2005\end{array}$ \\
\hline Age & $\begin{array}{l}\text { No information. } \\
\text { Older than } 20 \\
\text { years old }\end{array}$ & $\begin{array}{l}\text {...civilians in southern Sudan for the last } 20 \\
\text { years of the civil war... } \\
\text { San Diego Union Tribune - Aug 15, } 2004\end{array}$ \\
\hline Political party & $\begin{array}{l}\text { National } \\
\text { Congress Party }\end{array}$ & $\begin{array}{l}\text {... calling on Al-Bashir's National Congress } \\
\text { Party to... } \\
\text { CBS News - Sep 16, } 2006\end{array}$ \\
\hline Religion & Islam & $\begin{array}{l}\text {...al-Bashir has appreciated the centre's } \\
\text { establishment in Khartoum, which he described } \\
\text { as the capital for civilization, culture and Islamic } \\
\text { Sharia... } \\
\text { BBC news - Jul 5, } 2003\end{array}$ \\
\hline \multicolumn{3}{|l|}{$\ldots$} \\
\hline \multicolumn{3}{|l|}{ Relationships } \\
\hline$<$ is president of $>$ & Sudan & $\begin{array}{l}\text { President of the Republic, Field Marshal Omar } \\
\text { Al-Bashir, has affirmed that Sudan is } \\
\text { considered ... } \\
\text { Suna News Agency - July 20, } 2006\end{array}$ \\
\hline$<$ fights against $>$ & Sudan People's & ... Back in Sudan, al-Bashir led a series of \\
\hline
\end{tabular}




\begin{tabular}{|l|l|l|}
\hline & $\begin{array}{l}\text { Liberian Army } \\
\text { (SPLA) }\end{array}$ & $\begin{array}{l}\text { successful assaults on the SPLA in ... } \\
\text { BBC news - Oct 1, 2001 }\end{array}$ \\
\hline$<$ is supported by $>$ & Chad & $\begin{array}{l}\text { President Al-Bashir has lauded the efforts of } \\
\text { sister Chad for boosting the security and } \\
\text { stability in Darfur states... } \\
\text { BBC news - Sep 11, 2003 }\end{array}$ \\
\hline$<$ met with $>$ & Egyptian Prime & $\begin{array}{l}\text { Egyptian Prime Minister held talks in Cairo late } \\
\text { Sunday ... At the beginning of the } \\
\text { Egyptian-Sudanese higher committee meeting ... } \\
\end{array}$ \\
& & BBC news - Jul 28, 2002 \\
\hline$\ldots$ & & \\
\hline
\end{tabular}

The source attached to each concept and relationship may be displayed or hidden with user instruction.

For this particular task and more generally for several tasks in this domain, the basic types of concepts may include (Doddington et. al, 2004):

- Person

- Organization

- Country

- Event

- Location

Users may define their own concepts, some of which may be abstract, for example, terrorism. Users may also have different ways of representing concepts, for example, some may define "civil war" as an abstract concept while some may define it as an event that probably consists of several events.

Relationships include:

\begin{tabular}{|c|c|}
\hline Between people & $\begin{array}{l}<\text { is supporter of }>/<\text { is supported by }> \\
<\text { is opponent of }> \\
<\text { is associated with }> \\
<\text { met with }> \\
\ldots\end{array}$ \\
\hline Between people and location & $\begin{array}{l}<\text { is active at }> \\
<\text { met at }> \\
\ldots\end{array}$ \\
\hline $\begin{array}{l}\text { Between people and } \\
\text { organization/country }\end{array}$ & $\begin{array}{l}<\text { is leader of }> \\
<\text { is president of }> \\
\ldots\end{array}$ \\
\hline Between event and location & $\begin{array}{l}<\text { took place at }> \\
\ldots\end{array}$ \\
\hline
\end{tabular}




\begin{tabular}{|l|l|}
\hline Between organization and & $<$ is active at $>$ \\
location/country & $\ldots$ \\
\hline Between locations/countries & $<$ is part of $>$ \\
& $\ldots$ \\
\hline
\end{tabular}

The IR system is capable of extracting some types of entities and relationships with varying degrees of accuracy from about $40 \%$ to $80 \%$ (Florian et. al, 2004; Kambhatla, 2006).

Information extraction is incorporated to support the sense-making tool to see if it helps users with their sense-making processes and task performances.

Users may have different ways of representing their conceptual model. For example, a meeting between two people may be represented as a relationship between two concepts node of persons. It may also be represented as a concept node defined as an event with the people attending the meeting defined as attributes of that concept node. The tool will allow several forms of representation.

\section{Research Design and Methodology}

The research design involves user studies of the sense-making tool for structuring a concept space. Users will consist of 16-20 journalism and political science students. Each user will participate in three task sessions:

- an assigned task without the sense-making tool;

- an assigned task with the sense-making tool;

- a real task that the user needs to accomplish with the user's choice of system (with or without the sense-making tool).

Users will be screened for their ability to think-aloud without being distracted from performing such tasks.

Each task sessions takes about 90 minutes. The first 30 minutes the users will be given a brief introduction of the tool and a practice task for the training. The task performance will take about 60 minutes.

The assigned task will vary from information analysis, judgment, to decision making. The user task could be any task that users may need to perform, such as writing an essay for a class, preparing a presentation, and so on. The users will be asked to send their task description in advance to make sure the task is feasible for the information system and the time frame.

Data collection will involve:

1. Two questionnaires/interviews before the session to learn about user background and their background knowledge about the task;

2. A post-session Questionnaire for User Interaction Satisfaction (QUIS) (modified) to 
learn about how users think about the tool;

3. Think-aloud protocols recorded as users working on their tasks to learn about their evolving progress of the sense-making process;

4. Document produced by the tasks;

5. Search and use activity logs automatically recorded by the system.

Data analysis will begin with coding the collected materials according to the research questions. Among other things it will examine

- the relationships between the text and the extracted concepts and relationships;

- the development of concept maps and other representations over the course of the task;

- the difficulties users have in representing their conceptual model;

- the differences of the assigned tasks with and without the sense-making tool;

- the use of the different representations of the conceptual model in preparing the task report.

\section{Conclusions and Implications}

Helping users retrieve the right information is only half the battle; assisting users with making sense of what they found is the next frontier in information system design. This study will contribute to our understanding of sense-making processes and tools in the following aspects, and thereby give a better foundation for system design:

- Better understanding of how users organize their conceptual model, and how the different ways of organization would inform the design of sense-making tools;

- Better understanding of user processes of finding and using information to build a conceptual model of a problem or situation;

- What functions of the sense-making tool do or do not help users with their sense-making processes; what additional functions are suggested;

- What is the best way to implement the useful functions in the human-computer interface;

- Examining the types of information used and how they are used through the lens of users' sense-making process of a task situation, suggestions may be made as how automatic information extraction techniques may be used in information systems to facilitate users with their tasks.

\section{Acknowledgement}

This work is supported in part by DAPRA contract HR-0011-06-2-0001 (GALE). The author is grateful to Dagobert Soergel, her dissertation advisor for many fruitful discussions, and to the GALE user study team for their insightful inputs. 


\section{References}

Baldonado, M., Wang, Q., and Winograd, T., (1997). SenseMaker: an Information-Exploration Interface Supporting the Contextual Evolution of a User's Interests. in Proceedings of CHI '97, pp. 11-18

Dervin, B. (1992). From the Mind's Eye of the User: the Sense-Making Qualitative-Quantitative Methodology. In Glazier, J.D. and Powell, R.R. (Eds.) Qualitative Research in Information Management, pp. 61-84.

Doddington, G., Mitchell, A., Przybocki, M., Ramshaw, L., Strassel, S., Weischedel, R., (2004). The Automatic Content Extraction. (ACE) Program - Tasks, Data, and Evaluation, in the Proceedings of LREC 2004, pp. 837-840

Fikes, R., and Kehler, T., (1985). The Role of Frame-Based Representation in Reasoning, Communications of the ACM, vol. 28, no. 9, pp. 904-920.

Florian, R., Hassan, H., Ittycheriah, A., Jing, H., Kambhatla, N., Luo, X., Nicolov, N., Roukos, S., (2004). A Statistical Model for Multilingual Entity Detection and Tracking. HLT-NAACL 2004, pp. 1-8

Gaines, B. R., \& Shaw, M. L. G., (1995). Concept maps as hypermedia components. International Journal of Human-Computer Studies, 43(3), pp. 323-361.

Lehmann, F., (1992). Semantic networks, Computers \& Mathematics with Applications, vol. 23 , no. 2-5, pp. 1-50.

Kambhatla, N., (2006). Minority Vote: At-Least-N Voting Improves Recall for Extracting Relations. In proceedings of ACL 2006

Novak J. D., and Cañas, A. J., (2006). The Origins of the Concept Mapping Tool and the Continuing Evolution of the Tool. Information Visualization Journal 5, pp. 175-184 (January 2006).

PARC Intelligent Systems Laboratory, Glossary of Sensemaking Terms, http://www2.parc.com/istl/groups/hdi/sensemaking/glossary.htm

Qu, Y., (2007). Sensemaking, Information Seeking and Retrieval: Supporting Representation Construction in Sensemaking. Doctoral Dissertation. University of Michigan - Ann Arbor.

Wright, W., Schroh, D., Proulx, P., Skaburskis, A., and Cort, B. (2006). The sandbox for analysis -- concepts and methods. In Proceedings of CHI 2006, pp. 801--810.

Zhang, P., Plettenberg, E. L., Klavans, J. L., Oard, D. W., \& Soergel, D. (2007), Task-based Interaction with an Integrated Multilingual, Multimedia Information System: A Formative Evaluation. In proceedings of the Joint Conference on Digital Libraries (JCDL '07), June 2007, Vancouver 


\section{Appendix 1: Function List of the Sense-making Tool, Version 0}

\begin{tabular}{|c|c|c|c|}
\hline Component & Purpose & Function description & Using Information Extraction \\
\hline \multirow[t]{2}{*}{$\begin{array}{l}\text { 1. Search -> } \\
\text { Sense-making }\end{array}$} & \multirow[t]{2}{*}{$\begin{array}{l}\text { To select useful } \\
\text { information from the } \\
\text { search results and } \\
\text { organize it in the } \\
\text { workspace }\end{array}$} & $\begin{array}{l}1.1 \text { The user selects a piece of text (could } \\
\text { be by highlighted and right-clicking) } \\
\text { from the search result, and creates (could } \\
\text { be by dragging to the concept space area) } \\
\text { a concept and/or a relationship; the source } \\
\text { text is automatically attached with the } \\
\text { notes/arches created, source information } \\
\text { such as URL, date, language, and so on } \\
\text { are recorded }\end{array}$ & $\begin{array}{l}\text { 1.1. Te user selects a piece of } \\
\text { text, the system automatically } \\
\text { create the entities / } \\
\text { relationships / events in the } \\
\text { workspace; users may make } \\
\text { modifications (refer to } \\
\text { function } 3.1 \text { and } 3.2 \text { ) }\end{array}$ \\
\hline & & $\begin{array}{l}\text { 1.2 The user selects s a piece of text from } \\
\text { the search result, and attaches that text to } \\
\text { an existing concept or relationship }\end{array}$ & $\begin{array}{l}\text { 1.2. Te user selects a piece of } \\
\text { text, the system automatically } \\
\text { attaches it to existing } \\
\text { concepts and relationships; } \\
\text { users may make } \\
\text { modifications (refer to } 3.1 \\
\text { and } 3.2 \text { ) }\end{array}$ \\
\hline $\begin{array}{l}2 . \\
\text { Sense-making } \\
->\text { search }\end{array}$ & $\begin{array}{l}\text { To start a search } \\
\text { from the workspace }\end{array}$ & $\begin{array}{l}2.1 \text { The user may select a concept (or } \\
\text { multiple concepts) in the concept space } \\
\text { area, and starts a search in various search } \\
\text { models }\end{array}$ & $\begin{array}{l}2.1 \text { The user selects a concept } \\
\text { or relationship to search for, } \\
\text { such as search for an entity } \\
\text { that is known to the system } \\
\text { with name variations, or use } \\
\text { it as a character string query }\end{array}$ \\
\hline \multirow[t]{6}{*}{$\begin{array}{l}3 . \\
\text { Sense-making: } \\
\text { manipulation } \\
\text { of concepts and } \\
\text { relationships } \\
\text { (see also } \\
\text { 4. User } \\
\text { Interaction) }\end{array}$} & \multirow[t]{6}{*}{$\begin{array}{l}\text { To manipulate the } \\
\text { workspace, organize } \\
\text { information, form } \\
\text { understanding, etc. }\end{array}$} & $\begin{array}{l}\text { 3.0 Task specification - for example, } \\
\text { users may specify outline of a task and } \\
\text { subtask lists }\end{array}$ & $\begin{array}{l}3.0 \text { The system may do } \\
\text { information extraction on the } \\
\text { task description to identify } \\
\text { entities and relationships } \\
\text { mentioned in the task } \\
\text { description and link concept } \\
\text { map elements to the task } \\
\text { outline }\end{array}$ \\
\hline & & $\begin{array}{l}\text { 3.1 Users can represent concepts and } \\
\text { relationships in different formats: concept } \\
\text { maps, templates, and free-text notes }\end{array}$ & \\
\hline & & $\begin{array}{l}\text { 3.2 The system provides some } \\
\text { pre-defined structures: entity types, } \\
\text { relationship types, templates, and } \\
\text { outlines; users can also define their own } \\
\text { structures }\end{array}$ & \\
\hline & & $\begin{array}{l}3.3 \text { Users can create, modify, and delete } \\
\text { concepts and their attributes/slots (for } \\
\text { example, using a template-based } \\
\text { representation) }\end{array}$ & $\begin{array}{l}3.1 \text { Concepts may be created } \\
\text { by the system automatically } \\
\text { from the IE results; } \\
\text { automatically fill in the slots } \\
\text { of a concept }\end{array}$ \\
\hline & & $\begin{array}{l}3.4 \text { Users can create, modify, and delete } \\
\text { relationships; }\end{array}$ & $\begin{array}{l}3.2 \text { Relationships may be } \\
\text { created automatically from } \\
\text { the IE results }\end{array}$ \\
\hline & & $\begin{array}{l}3.5 \text { Users can attach source article/snippet } \\
\text { to concepts (attributes) and relationships }\end{array}$ & \\
\hline $\begin{array}{l}\text { 4. User } \\
\text { interaction }\end{array}$ & $\begin{array}{l}\text { To support users' } \\
\text { interaction with the } \\
\text { presentation of their } \\
\text { conceptual model. } \\
\text { To support } \\
\text { discovery of patterns }\end{array}$ & $\begin{array}{l}\text { 4.1 The system should support graphical } \\
\text { layout at different levels of detail of } \\
\text { concepts and relationships (for example, } \\
\text { aggregating contacts between country } \\
\text { representatives into contacts between } \\
\text { countries) }\end{array}$ & \\
\hline
\end{tabular}




\begin{tabular}{|c|c|c|c|}
\hline & \multirow[t]{3}{*}{ and abstraction } & $\begin{array}{l}\text { 4.2 The system should offer the option of } \\
\text { differentiating the presentation of } \\
\text { different types of concepts and } \\
\text { relationships (possibly using different } \\
\text { color schemes or highlights) }\end{array}$ & \\
\hline & & $\begin{array}{l}4.3 \text { Users can zoom in and out to view } \\
\text { closely at part of a conceptual model or to } \\
\text { get an overview of the whole conceptual } \\
\text { space. }\end{array}$ & \\
\hline & & $\begin{array}{l}\text { 4.4 Users can define the types of } \\
\text { information to be displayed or } \\
\text { highlighted (for example show or hide } \\
\text { certain types of entities and relationships) }\end{array}$ & \\
\hline \multirow[t]{3}{*}{$\begin{array}{l}\text { 5. Report } \\
\text { writing support }\end{array}$} & \multirow[t]{3}{*}{$\begin{array}{l}\text { To select certain } \\
\text { pieces of } \\
\text { information in the } \\
\text { workspace to turn } \\
\text { into a report }\end{array}$} & $\begin{array}{l}\text { 5.1 The user selects concepts and } \\
\text { attributes (may also specify evidence } \\
\text { details) to be included in the report, the } \\
\text { system constructs an outline of the report } \\
\text { based on a default or user specified } \\
\text { format }\end{array}$ & \\
\hline & & $\begin{array}{l}\text { 5.2 Hyperlinks to a Web source, local } \\
\text { files on personal computer, or the } \\
\text { location of a print source should be } \\
\text { preserved }\end{array}$ & \\
\hline & & $\begin{array}{l}5.3 \text { The user can choose the editor they } \\
\text { work in, for example, MSWord }\end{array}$ & \\
\hline \multirow[t]{2}{*}{ 6. History } & $\begin{array}{l}\text { User activity history } \\
\text { shown to the users; } \\
\text { (may be part of or } \\
\text { built from } 6.2 \text { ) }\end{array}$ & $\begin{array}{l}6.1 \text { should be able to review action } \\
\text { history (the adding and modification of } \\
\text { concepts, relationships, and evidences), } \\
\text { and (possibly) go back to a previous } \\
\text { conceptual structure from the history }\end{array}$ & \\
\hline & Activity log & $\begin{array}{l}6.2 \text { a fine-grained log of user activity: key } \\
\text { strokes and clicks with time stamp, result } \\
\text { sets returned and what was shown on the } \\
\text { screen. It must be possible to trace all } \\
\text { user actions in detail from the log. Basis } \\
\text { for } 6.1\end{array}$ & \\
\hline
\end{tabular}

